\title{
Is the US ready for ICD-10?
}

$\mathrm{T}$ here is a code for collisions between pedestrians and roller skaters. There is a code for getting sucked into a jet engine. If you get struck by a duck, there is a code for that too. There are, in fact, about 68000 diagnostic codes and 72000 inpatient procedure codes in the 10th edition of the International Classification of Diseases (ICD-10). Medical providers and insurvery familiar with them, because Oct. 1 has come.

That was the deadline, already twice delayed, for the US health care system to finally join the rest of the industrialized world in using the ICD-10 coding system. All entities covered under the Health Insurance Portability and Accountability Act - hospitals, clinics, nursing homes, insurance companies, government health programs and any other organization that works with electronic health information - must use the new codes when billing for medical services.

The transition will bring a muchneeded boost in precision to the US health system, which for 35 years has been using the much broader ICD-9 coding system (about 15000 diagnostic codes and 4000 inpatient procedure codes). The new system will allow health providers to better measure quality of care, identify health trends and track early warning signs of outbreaks. It will also ers in the United States will soon become

generate more data for medical researchers and bring the US in line with international standards. There are fears, however, that the transition may be bumpier than expected and that some medical providers and insurers, smaller ones in particular, are not prepared for the change.

One very large entity that will be affected - the Centers for Medicare and Medicaid Services (CMS), which processes millions of medical claims every day - insists it is ready and that "patient care will be business as usual." Its claims-processing systems have been completely updated to accept ICD-10 codes, and it has "conducted an unprecedented level of testing to help providers prepare for the transition," according to a statement emailed to $C M A J$ by CMS press officer Jibril Boykin.

"Medicare beneficiaries will be able to get the same services as before, and their coverage for items will not change," read the statement. "This transition to a new coding system is about how a doctor or other health care provider submits a bill for payment. If a provider does not submit a valid ICD-10 code on the claim, they have the opportunity to correct the error and resubmit the claim."

But some CMS observers aren't so confident in the government agency's preparations, citing the disastrous rollout of the national health insurance exchange under Obamacare in 2013 as setting an

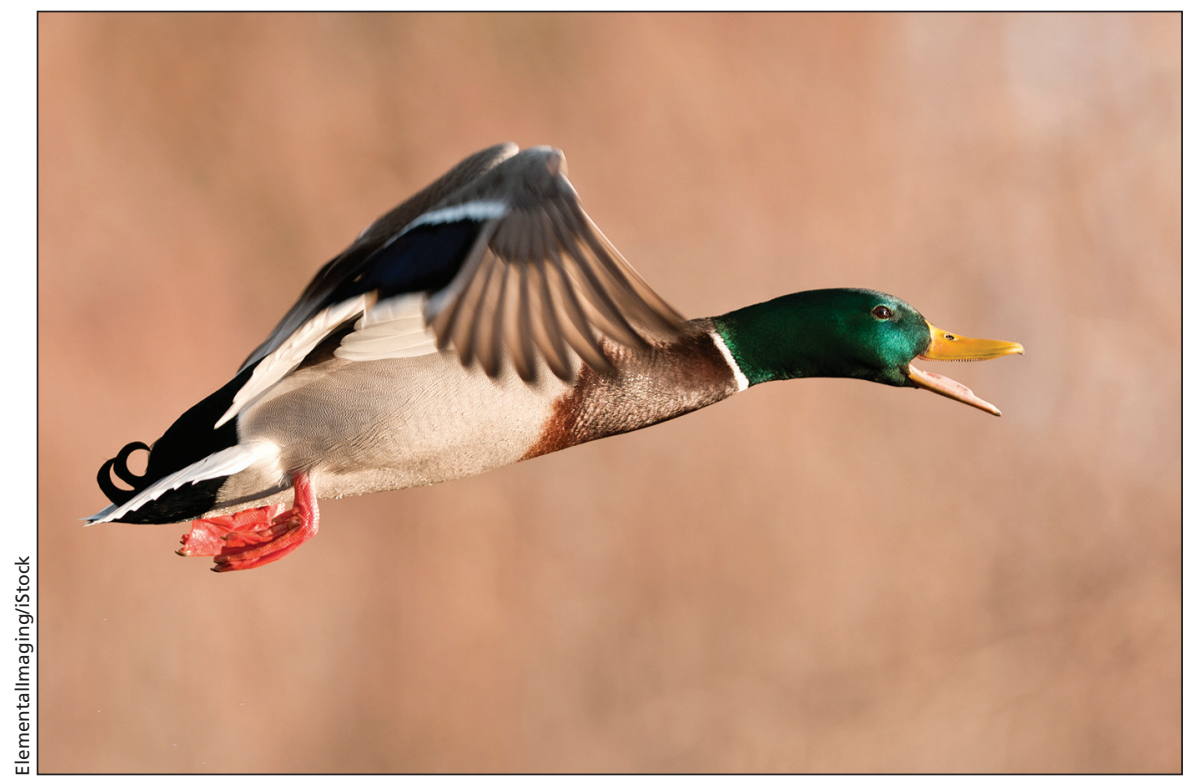

Injured after a run-in with an angry duck? There is a medical code for that. ominous precedent. Even the CMSappointed ICD-10 ombudsman, Dr. William Rogers, acknowledged that there will likely be "a rocky couple of months" after Oct. 1. The US Government Accountability Office (GAO), which recently released a report on CMS's ICD-10 preparations, also noted that no amount of testing can guarantee problems won't arise when a new, large-scale system of this sort goes live.

"Our report message notes that CMS has finished updating its systems with the changes that it determined were needed to process the new ICD codes," Valerie Melvin, director of information management and technology resource issues at GAO, noted in an email. "Further, we stressed that, while CMS's actions to update, test, and validate its systems, and plan for contingencies can help mitigate risks and minimize the impacts of system errors, the extent to which any such errors will affect the agency's ability to properly process claims cannot be determined until CMS's systems begin processing the ICD-10 codes."

Meanwhile, other health providers have reported "shaky optimism" about the transition, with many admitting they were not on track to meet the Oct. 1 deadline. Others are concerned about the increased workload for doctors and other health workers, who will have to report a lot more information. Billing in some fields of medicine, such as orthopedics, will become particularly complex, with dozens of new codes replacing each old code.

Some states, including California and Maryland, have already been granted special provisions because their claimsprocessing systems for Medicaid programs will not be able to process ICD10 payments. And across the country, many smaller providers are expecting delays in processing medical claims that will cause untenable disruptions to their cash flow. This has prompted some banks to offer special ICD-10 lines of credits to medical practices to ensure they have enough operating capital. Roger Collier, CMAJ 